\title{
MannaAcademy: impulsionando o protagonismo feminino através de uma rede interinstitucional de extensão universitária
}

\author{
Daniela Eloise Flôr ${ }^{1,5}$, Eduardo Henrique Molina da Cruz ${ }^{1}$, Ayslan Trevisan Possebom ${ }^{1}$, \\ Carlos Roberto Beleti Junior ${ }^{2}$, Rodrigo Hübner ${ }^{3}$, Paulo César Gonçalves ${ }^{3}$, \\ César Alberto da Silva ${ }^{4}$, Linnyer Beatryz Ruiz Aylon ${ }^{5}$ \\ ${ }^{1}$ Instituto Federal do Paraná (IFPR) \\ Campus Paranavaí - PR - Brasil \\ ${ }^{2}$ Universidade Federal do Paraná (UFPR) \\ Campus Jandaia do Sul - PR - Brasil \\ ${ }^{3}$ Universidade Tecnológica Federal do Paraná (UTFPR) \\ Campus Campo Mourão - PR - Brasil \\ ${ }^{4}$ Instituto Federal de São Paulo (IFSP) \\ Campus Presidente Epitácio - SP - Brasil \\ ${ }^{5}$ Universidade Estadual de Maringá (UEM) \\ Maringá - PR - Brasil \\ \{daniela.flor, eduardo.cruz, ayslan.possebom\}@ifpr.edu.br, \\ carlosbeleti@ufpr.br, \{rhubner,paulocg\}@gmail.com, \\ cesar@ifsp.edu.br, lbruiz@uem.br
}

\begin{abstract}
MannaAcademy is a project that drives female protagonism towards gender equality in technological areas. The joint efforts of the Manna Team resulted in an interinstitutional network that, by extension activities, shares knowledge, space and materials. The iniciative spreaded its actions to show society the impacts of gender inequality and the need for the presence of women in computer science, microeletronics and engeneerings.
\end{abstract}

Resumo. O MannaAcademy é um projeto que impulsiona o protagonismo feminino em direção ao equilíbrio de gênero em áreas tecnológicas. A articulação dos integrantes do Grupo Manna resultou em uma rede interinstitucional que, por meio da extensão universitária, compartilhou saberes, espaços e materiais. A iniciativa capilarizou suas ações para mostrar à sociedade os impactos da disparidade de gênero e a necessidade da presença feminina na computação, na microeletrônica e nas engenharias.

\section{Introdução}

Uma das interações esperadas de uma universidade é a participação no processo dialético de transformação social. [Nunes and Silva 2011] ressaltam que transformar e ser transformada é parte de um cenário dinâmico que deve ser inclusivo, criativo e emancipatório. Dentre os pilares da educação universitária, a extensão tem essa responsabilidade. 
O projeto MannaAcademy promoveu a interlocução entre docentes e discentes do ensino básico e do ensino superior, formando uma rede de estímulo à participação e à formação de meninas e mulheres em carreiras de engenharias, computação e microeletrônica. De acordo com [Main and Schimpf 2017], diversas iniciativas se propõem a incentivar a participação feminina nessas áreas, colaborando para desmistificar adversidades relacionadas à atuação profissional das mulheres e possibilitando que, desde os anos iniciais do ensino, as meninas possam interessar-se pelas áreas. $\mathrm{O}$ projeto atuou com $\mathrm{o}$ público feminino por meio de atividades de extensão que ocorreram na forma de cursos, oficinas e participações em mostras de profissões, eventos de inovação e intervenções educacionais.

Os participantes do MannaAcademy integram o Grupo Manna de Pesquisa e Desenvolvimento em Engenharia de Computação Invisível. O grupo é membro do INCT NAMITEC, é certificado pela SBMicro, tem mais de 20 anos de experiência e é formado por 01 bolsista CNPq nível 1, 01 pós-doutoranda bolsista - PNPD/CAPES, 15 doutores, 9 mestres, 06 alunos de mestrado do Programa de Pós-Graduação em Ciência da Computação da UEM, 04 alunos de doutorado da UFMG, 04 alunos de trabalho de conclusão de curso e 02 estagiários de Licenciatura em Computação.

O Grupo Manna realiza pesquisas em temas que se encontram na fronteira tecnológica para o desenvolvimento do país, sem ignorar os impactos multifacetados desses avanços, como o que reverbera na educação. Por isso, a iniciativa MannaAcademy buscou e foi contemplada pela Chamada CNPq/MCTIC No 31/2018 Meninas nas Ciências Exatas, Engenharias e Computação. Com isso, o Grupo Manna ganhou um expressivo reforço com mais 21 bolsas exclusivas para mulheres, sendo: 15 bolsas de iniciação científica júnior para alunas do ensino médio, 03 bolsas de iniciação científica para alunas do ensino superior e 03 bolsas de apoio técnico em extensão no país (ATP) para professoras de escolas públicas.

A coordenação do projeto deu início à articulação do trabalho em rede disponibilizando as bolsas de iniciação científica para seleção junto à Universidade Estadual de Maringá, UFPR Campus Jandaia do Sul e UTFPR Campus Campo Mourão. As bolsas de apoio técnico e de iniciação científica júnior foram distribuídas entre o IFPR Campus Paranavaí, Colégio Estadual Itacelina Bittencourt em Cianorte-PR, Instituto de Educação Estadual de Maringá-PR, Colégio Estadual Professora Ivone Castanharo em Campo Mourão-PR, Colégio Estadual Nilo Cairo em Apucarana-PR e Colégio Estadual Rui Barbosa em Jandaia do Sul-PR. Adicionalmente, uma equipe de voluntárias do IFSP Campus Presidente Epitácio juntou-se ao projeto realizando ações na Escola Consuelo Magalhães Castro Dona e na Escola Marina Amarante Ribeiro Vasques Sanches em Presidente Epitácio-SP.

O intercâmbio entre bolsistas, professoras e pesquisadores de instituições tão diferentes contribuiu para o fortalecimento do trabalho em equipe em uma dimensão bastante ampla. Ao mesmo tempo que favoreceu o compartilhamento dos recursos institucionais, valorizou os saberes individuais e capilarizou o impacto de suas ações atuando na formação de alunas do norte e noroeste do Paraná, chegando inclusive ao estado de São Paulo. Apesar do projeto ter sido operacionalizado pelas bolsistas, as ações beneficiaram alunas e alunos em todos os locais onde foram executadas. 


\section{Projeto MannaAcademy: Formas de Atuação}

A coordenação do projeto iniciou as atividades correlacionando seus objetivos com as competências e recursos dos envolvidos e suas respectivas instituições de ensino. Para tanto, a equipe organizou os trabalhos da seguinte forma:

- Avaliação in loco das instituições parceiras: nesta etapa foram realizadas visitas e reuniões para definição das responsabilidades institucionais, dos espaços físicos disponíveis, da estratégia de aporte das ações e o contato com as escolas de educação básica;

- Planejamento e organização: mapeamento das habilidades, definição das equipes, elaboração dos planos de trabalho, cronograma de atividades, definição do conteúdo programático, metodologia das aulas e periodicidade dos encontros;

- Capacitação das equipes: realização dos encontros periódicos entre membros do Grupo Manna com as bolsistas de apoio técnico em extensão no país, de iniciação científica e de iniciação científica júnior, desenvolvimento de protótipos, confecção das peças do diorama;

- Execução das atividades: organização e execução das atividades junto às escolas públicas parceiras;

- Diálogos com a sociedade: promovidos pela publicização das ações em sites, redes sociais e mídia televisiva, participação em eventos de inovação, feiras de ciência, feiras agropecuárias, mostras de profissões e realização de oficinas e palestras com alunos da educação básica e do ensino superior;

- Organização e execução do MannaDay: evento periódico destinado à socialização das atividades das equipes.

\section{Resultados e Impactos do Projeto MannaAcademy}

A realização de uma pesquisa com 13 bolsistas e voluntárias, tanto do ensino médio quanto da graduação, forneceu um panorama sobre a percepção delas a respeito do projeto MannaAcademy. Um breve compilado dos resultados está exposto na Figura 1. A questão 1, acerca da participação das bolsistas em iniciativas de engajamento feminino em áreas tecnológicas, mostra que para $85 \%$ a experiência foi novidade. Após o envolvimento no projeto, informação obtida pela questão 2 , o interesse em participar de outras ações só não alcançou $8 \%$ das participantes. Na questão 3, esboçada no gráfico de barras na cor laranja, a influência do projeto em escolhas profissionais tendeu do nível intermediário ao máximo, já a percepção sobre a importância do projeto, representada no gráfico pelas barras azuis, foi bastante expressiva e chegou a $92,3 \%$.

O caráter distribuído do projeto causou impacto em várias cidades, pesquisadores e bolsistas atuaram em Maringá, Paranavaí, Jandaia do Sul, Apucarana, Mandaguari, São Pedro do Ivaí, Campo Mourão, Cianorte e Presidente Epitácio. Ao todo, pelo menos 480 alunas e alunos e 40 professoras e professores da educação básica foram beneficiadas(os) por meio de cursos, oficinas ou palestras sobre: Robótica, Internet das Coisas, Automação com Arduino, Utilização de kits IEEE para ensino de eletrônica básica, Manutenção de Computadores, Ensino de programação utilizando blockly, Desenvolvimento de atividades na plataforma Code.org, Capacitação de alunos para competições de programação e Pensamento Computacional. 


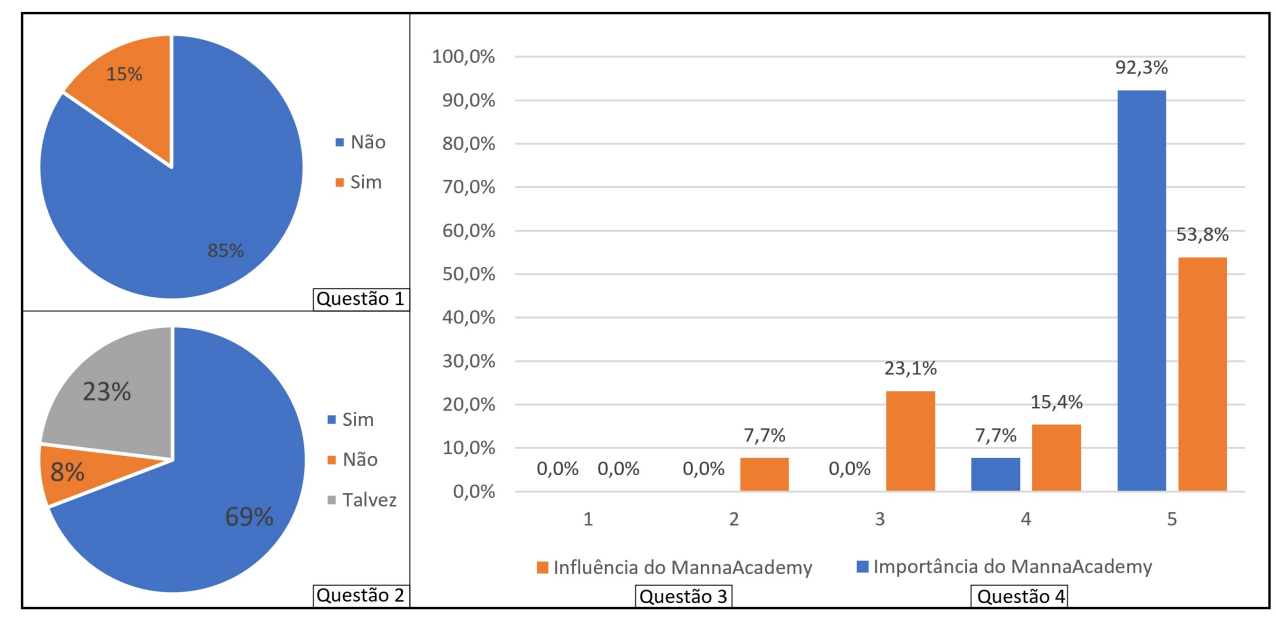

Figura 1. Alguns resultados do MannaAcademy

Adicionalmente, um público significativo de alunas e alunos de escolas municipais, estaduais e federais conheceram a iniciativa MannaAcademy devido à participação em mostras de profissões, eventos científicos e feiras de inovação. Dentre eles, cita-se:

- Semana Nacional de Ciência e Tecnologia - IFSP;

- X Semana Científica e Cultural do Instituto de Educação Estadual de Maringá;

- VII Feira de Inovação Tecnológica do IFPR - Paranavaí;

- IV Femax da Escola Fatecie Max - Paranavaí;

- II Seminário de Integração das Pesquisas do Núcleo Base - Paranavaí;

- VI Semana de Tecnologia da Informação de Paranavaí;

- III Simpósio de Licenciaturas em Ciências Exatas - Jandaia do Sul;

- XI Semana Integrada de Ensino, Pesquisa e Extensão na UFPR - Jandaia do Sul;

- Semana do Meio Ambiente da UFPR - Jandaia do Sul;

- Evento de Tecnologias Informacionais no Colégio Vera Cruz - Mandaguari;

- Feira de Cursos e Profissões nos Campi Avançados da UFPR - Jandaia do Sul;

- Feira Tecnológica do Colégio Estadual Unidade Pólo - Jandaia do Sul;

- Mostra Cultural do Colégio Estadual Carlos Silva - São Pedro do Ivaí;

- Visita guiada dos integrantes da Associação Florart Vida - Jandaia do Sul;

- Visita guiada dos alunos do Colégio Vera Cruz - Mandaguari;

- Empreendeweek 2019 - Campo Mourão;

- Mostra de profissões na UTFPR - Campo Mourão;

- Feira de Ciências do Colégio Professora Ivone Castanharo - Campo Mourão.

O trabalho do Grupo Manna também chegou aos empresários dos segmentos da indústria, comércio e agropecuária em eventos como: Inovatech, IrrigaParaná, Expoingá e Pint of Science Maringá.

\section{Conclusões e Trabalhos Futuros}

A experiência com o MannaAcademy mostrou que o interesse das meninas por áreas como a computação, engenharias ou microeletrônica pode ser estimulado por meio de iniciativas que as aproximem deste universo em nível escolar oportuno, ou seja, durante o ensino médio, período em que as escolhas profissionais ocupam o imaginário adolescente. 
Apesar da temática técnica abordar assuntos nada triviais, como, por exemplo, automação e internet das coisas, a democratização do conhecimento universitário é viável e verificou-se que a parceria entre os atores da educação básica e do ensino superior pode ser possível, exitosa e empoderadora. Essa parceria foi além, permitiu a aplicação prática do conhecimento e contribuiu para uma formação mais integral dos universitários, e estimulou a mobilidade interinstitucional entre estudantes de níveis de ensino diferentes.

Outro aspecto relevante que despontou durante a execução das ações do projeto MannaAcademy foi a reflexão sobre a Agenda 2030 para o Desenvolvimento Sustentável, conforme os objetivos abordados em [ONU 2015] que visam a paz, a prosperidade e a parceria entre as pessoas e o planeta. Dentre as metas e objetivos apontados pelo plano, algumas foram bastante articuladas no projeto na fase de construção dos protótipos, sejam elas: objetivo 4 - Educação de qualidade, 5 - Igualdade de gênero, 6 - Água Potável e saneamento, 7 - Energia limpa e acessível e 11 - Cidades e comunidades sustentáveis.

Desta forma, verificou-se que, fazer parte de uma rede de aprendizagem colaborativa, que promoveu o intercâmbio entre sujeitos, saberes, laboratórios e tecnologias, aliada à discussão de problemas reais do planeta como equidade de gênero na atuação profissional, só aumentou a relevância da execução do MannaAcademy. O projeto oportunizou minimizar mitos, encurtar distâncias, fomentar a criatividade e, principalmente, potencializar ações com práticas colaborativas.

Pela dinâmica de um projeto em rede, intercorrências com sincronização de agendas, alocação de espaço físico e deslocamento foram obstáculos a serem superados, mas, indubitavelmente, o projeto superou as expectativas iniciais em números e extensão. Por isso, verifica-se a necessidade da continuidade de projetos com o propósito de atração do público feminino para a área das exatas, principalmente quando é possível empregar uma rede de ações universitárias extensionistas.

\section{Agradecimentos}

Este trabalho tem o apoio do CNPq (Processo/MCTIC 442433/2018 e 426119/2016), bem como das demais instituições de ensino envolvidas.

\section{Referências}

Main, J. B. and Schimpf, C. (2017). "The underrepresentation of women in computing fields: A synthesis of literature using a life course perspective". IEEE Transactions on Education, 60(4):296-304.

Nunes, A. L. P. F. and Silva, M. B. C. (2011). "A extensão universitária no ensino superior e a sociedade". Revista Mal-Estar e Sociedade, 4(7):119-133.

ONU (2015). "Transformando nosso mundo: A agenda 2030 para o desenvolvimento sustentável". https://nacoesunidas.org/pos2015/agenda2030/. Outubro. 